\title{
Replicate ice-coring system testing
}

\section{Jay A. JOHNSON, Nicolai B. MORTENSEN, Christopher J. GIBSON, Joshua J. GOETZ, Alexander J. SHTURMAKOV}

\author{
Ice Drilling Design and Operations (IDDO), Space Science and Engineering Center (SSEC), \\ University of Wisconsin-Madison, Madison, WI, USA \\ E-mail: jay.johnson@ssec.wisc.edu
}

\begin{abstract}
Drilling the WDC06A borehole at the West Antarctic Ice Sheet (WAIS) Divide with the Deep Ice Sheet Coring (DISC) drill began in December 2007 and was successfully completed in December 2011 to a depth of $3405 \mathrm{~m}$. The design and construction of a replicate coring system for use with the existing DISC drill began in 2010. In January 2012, the new replicate coring system was tested in the parent borehole at WAIS Divide. While a full deviation was not completed during the test period, much was learned about the mechanical, electrical and operational aspects of the system. Extensive testing and modifications were done over the northern/boreal summer to prepare the system for the upcoming and final season of the project. Further tuning of the system continued during the 2012/13 field season at WAIS Divide. This paper identifies the issues found with the system during the initial test season and discusses solutions, methods and testing done to arrive at an operational system.
\end{abstract}

KEYWORDS: Antarctic glaciology, ice and climate, ice coring, ice engineering

\section{INTRODUCTION}

The final design and manufacture of the replicate coring system began in 2010 (Gibson and others, 2014; Mortensen and others, 2014) after many years developing the concept of how replicate coring would be accomplished at the West Antarctic Ice Sheet (WAIS) Divide camp. The original design of the Deep Ice Sheet Coring (DISC) drill included features to facilitate future addition of replicate coring functionality, including modular components and a sonde diameter limited to $134 \mathrm{~mm}$ above the chip collection barrels (Mason and others, 2007). Computer modeling, building prototypes, and testing to validate designs was an integral part of the replicate coring system development. The replicate coring system is described in detail in Gibson and others (2014) (Fig. 1). The full system was assembled and tested for the first time at WAIS Divide in January 2012 and was shown to perform well, although there were a few unforeseen complications in trying to create a deviation. A few aspects of the design needed to be addressed before the system was going to be able to create a deviation and collect replicate cores.

\section{REPLICATE CORING PROCESS OVERVIEW}

The process of creating a deviation with the replicate coring system is accomplished in three basic steps. In each step, the drill is lowered to a target depth and actuator levers near the top and bottom of the sonde are extended on opposite sides to tip the sonde and engage the cutter on the high side of the borehole.

In the first step, a broaching cutter is used to remove material like a rasp in an upward motion. The cut is made over a distance of $\sim 15 \mathrm{~m}$ with a depth of cut of $\sim 4 \mathrm{~mm}$ per pass. Multiple passes are performed until the total radial depth of the cut on the high side of the borehole is 75$100 \mathrm{~mm}$. At this point the inclination of the sonde is $\sim 1^{\circ}$ greater than that of the parent borehole and is measured using the sonde's inclinometer with an accuracy of better than $0.1^{\circ}$.
Once this inclination is achieved, the broaching cutter is replaced with a rotary face mill to begin the second step. In this step, a ledge is created by removing material from the gradual slope at the lower extreme of the deviation created by the broach. The milling cutter, rotating at $\sim 80 \mathrm{rpm}$, is lowered to remove material over a distance of $\sim 1 \mathrm{~m}$, creating a flat ledge $\sim 100 \mathrm{~mm}$ measured radially.

In the third step, the milling head is replaced with a coring head. Just above the target depth the actuators tip the sonde and the coring cutter is lowered onto the ledge to begin to cut the first replicate core. A detailed process description is provided by Gibson and others (2014).

\section{INITIAL FIELD TEST RESULTS}

At the end of the 2011/12 season at WAIS Divide, 3 weeks were allocated for testing of the replicate coring system. This was the first time the complete system had been assembled. Numerous start-up tests were completed to verify that the actuators and control systems were functioning properly.

The broaching cutting method was first tried to create a deviation. After numerous attempts, it was determined that the broaching cutter (Fig. 2a) would not cut. It was later determined this was due to a combination of factors but was primarily a function of cutter geometry.

Next, a milling cutter (Fig. 3a) was used to attempt to create the deviation by a combination of radial and axial cutting. This cutting method did start to create a deviation. However, the entire diameter of the borehole was being enlarged because the cutter head was orbiting around the hole instead of following the desired path. This is evident in Figure $4 \mathrm{~b}$, the borehole image from a depth of $3000 \mathrm{~m}$.

It was found through cutter torque and weight-on-bit readings, and from borehole video, that despite a smooth cable payout at the surface, the drill moves up and down in the borehole with a stop-start or 'stick-slip' motion at slow feed rates. This is likely the result of two separate factors: the friction of the winch cable lying on the borehole wall and 


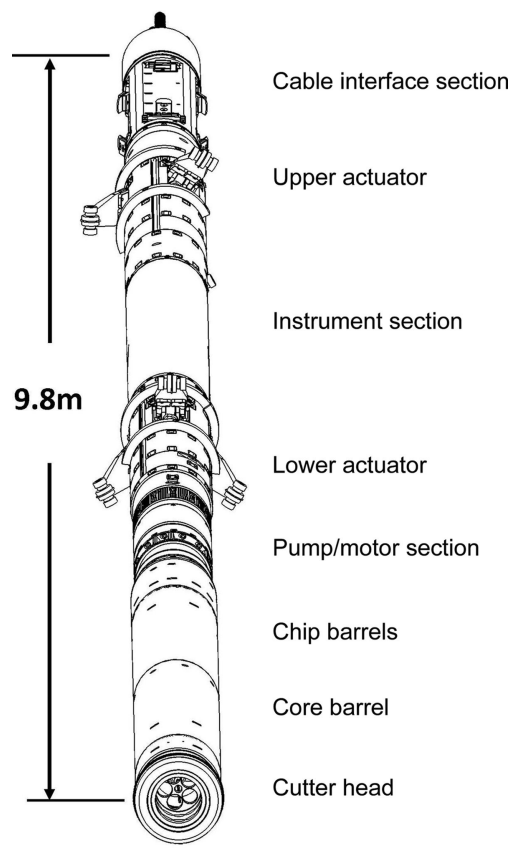

Fig. 1. Replicate coring system sonde.

the friction of the drill and actuator arms acting on the borehole wall. Attempts were made to get the drill into a stable cutting state by milling a shallow ledge in the borehole and then landing the milling head on the ledge. To achieve this, the milling head was fitted with a face-cutting bit and an axial shoe, which was made in the field. Once a ledge was created, weight could be applied to the bit so the

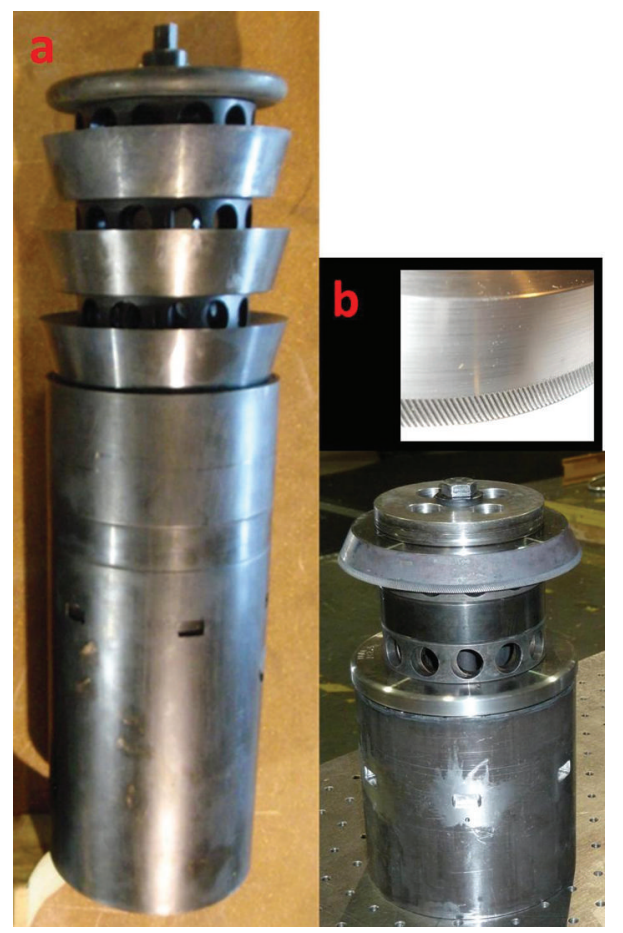

Fig. 2. (a) Original broaching head with cutters mounted for cutting in the down stroke. (b) New broaching head with serrated toothed cutter mounted for cutting in the up stroke. The inset shows an enlarged view of the serrated edge. Note that both heads are shown resting on a table in a position inverted from how they would be deployed in the borehole.

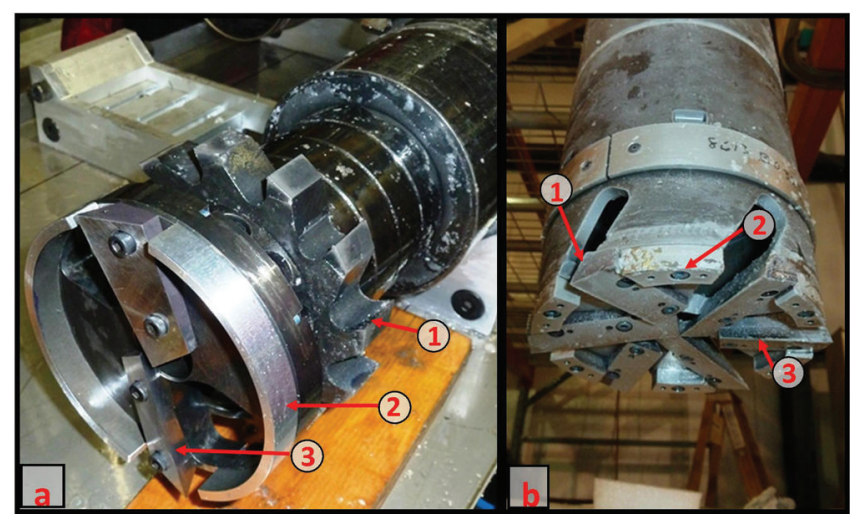

Fig. 3. (a) Original milling head with sawtooth cutters for radial cutting and an end cutter attachment with helical shoes for face milling. (b) New six-cutter milling head fitted with axial and radial shoes. In each panel, basic functional components are highlighted: 1. radial cutting edge; 2 . helical face shoes; 3 . face-cutting edge.

drill would penetrate smoothly. Attempts to create this ledge were not successful.

Three primary issues with the replicate coring system remained to be addressed at the end of the 2011/12 season: the axial stick-slip of the sonde, sonde flexure, and the design of the broaching and milling heads. To address these issues, modeling was needed to quickly investigate the full range of conditions the drill would see in operation. Physical testing of the sonde and cutters was also needed to identify more precisely the mechanical characteristics of the system and to validate the models.

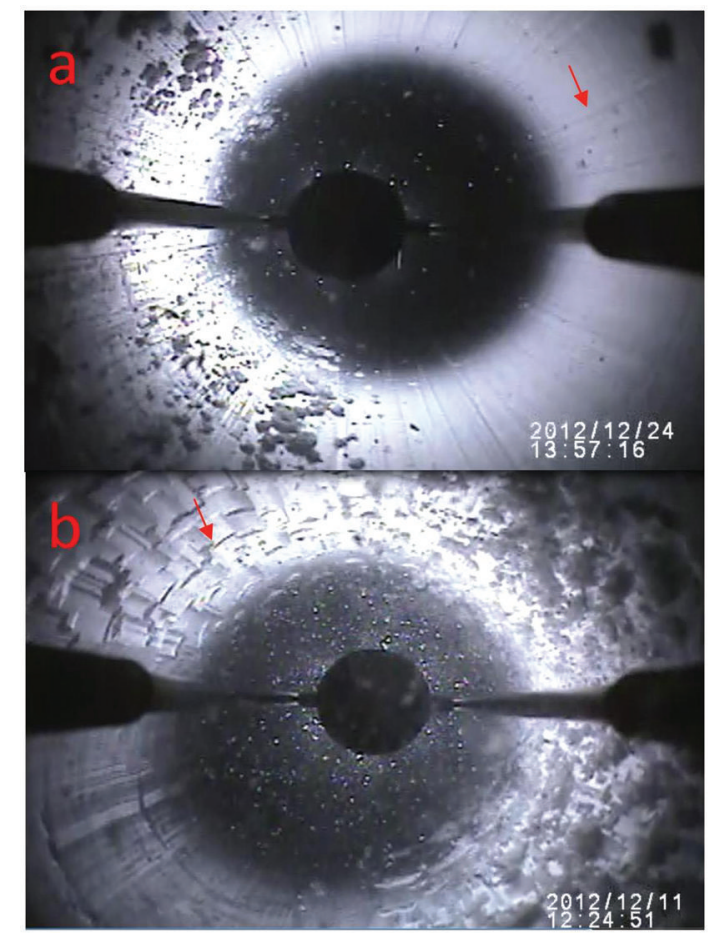

Fig. 4. (a) The parent borehole at a depth of $\sim 10 \mathrm{~m}$ below the first deviation shows axial marks from anti-torque blades (arrow). Ice chips are visible on the opposite side of the borehole. No circumferential marks are visible from coring the parent borehole. (b) The parent borehole at the depth of the first deviation shows circumferential cutter marks (arrow) around the entire diameter. 


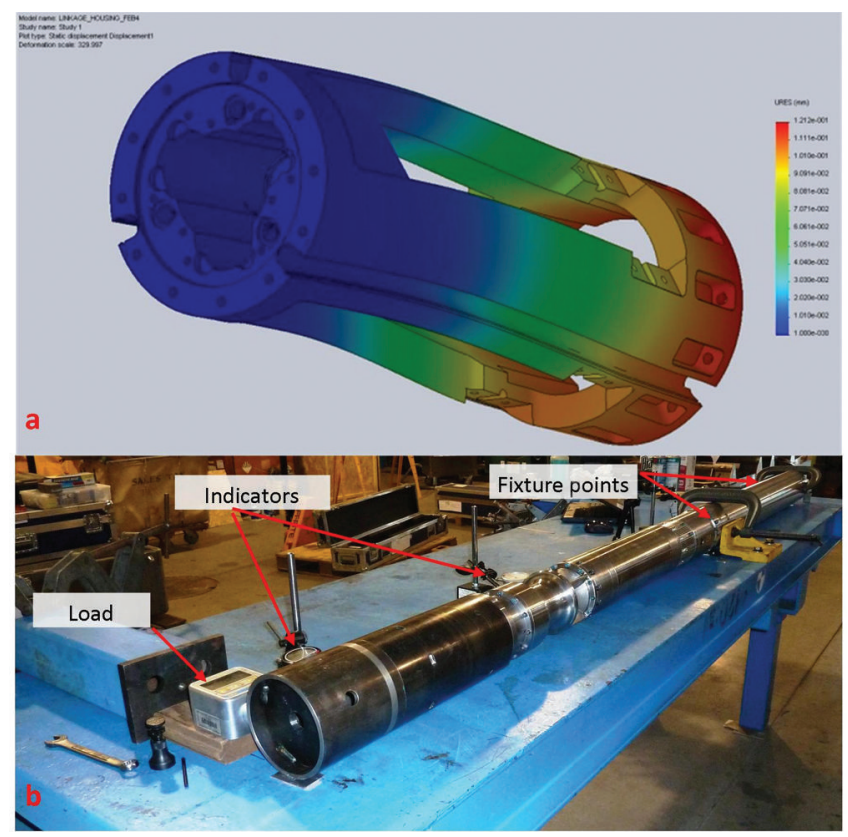

Fig. 5. (a) Finite-element model of actuator housing. (b) Physical measurement of motor section deflection.

\section{SONDE FLEXURE}

Discrete radial load points (e.g. levers, cutter head and stabilizer rings) along the length of the sonde lead to flexure of the system. This flexure can lead to reduced radial force at the cutter, making it easier for the cutter to orbit or precess around the borehole. In some cases, sonde flexure can interfere with engagement of the cutter in the ice. Both of these were limiting factors during the WAIS Divide test season. To evaluate sonde flexure and its numerous impacts on sonde performance, additional finite-element analysis (FEA) and physical measurements were performed to refine the mechanical parameters of each module of the sonde. Figure $5 \mathrm{a}$ shows an example of an FEA used to determine module mechanical parameters, while Figure 5b shows an example of physical measurements of these parameters where the complexity of the assembly made FEA less practical.

With refined values of physical parameters for each module identified, a FEA model of the entire sonde in the borehole was created. The screen section was found to be the main source of the flexure. The issue was resolved with two modifications. First, modular screen sections of $0.75 \mathrm{~m}$ and $1.5 \mathrm{~m}$ were made to replace the original $2.25 \mathrm{~m}$ sections. By adding or removing sections, the sonde could be kept as short as possible for the given drilling operation, thereby minimizing total flexure. The second modification was simply to double the wall thickness of the tubes, thereby increasing stiffness by more than a factor of two.

Next, using the governing statics equations, a Mathcad model was created to quickly provide results for the numerous iterations required to represent the sonde in each step of the deviation. This model was used to predict contact points on the sonde due to drill flexure, to estimate the force at the cutters and to determine the appropriate size and location of stabilizer rings (Gibson and others, 2014). Figure 6 shows an output of the model. Once validated, the model could quickly predict the performance of the sonde and the available force at the cutter head.

To verify the Mathcad model, physical measurements of the flex of the sonde under the loads applied by the actuators and by gravity were made with the sonde tilted at $6^{\circ}$. This angle approximates the angle of deviation at the point of highest inclination in the parent borehole. A fixture that could orientate the sonde properly and simulate a round and oval borehole, while still allowing the operator to see and measure the sonde's movement, was essential. A specially designed test tower was built as shown in Figure 7. Short sections of steel tubing, which could be positioned at any desired location along the length of the aluminum tower, were used to simulate the points at which the sonde contacts the borehole wall. The tubes were split so spacers could be added in order to simulate the varying shape of the borehole as a deviation was being formed. Leaving the rest

\begin{tabular}{|c|c|c|c|}
\hline $\begin{array}{l}\text { Top Ring: } \\
\text { Upper Ring: } \\
\text { Lower Ring } \\
\text { Shoe: } \\
\text { Cutter: } \\
\text { Effort Upper: } \\
\text { Effort Lower: } \\
\text { Duty: } \\
\text { Period: } \\
\text { Skew Table: } \\
\text { AutoAz:: } \\
\text { Mode: } \\
\text { Cable Speed: } \\
\text { Pump Speed: } \\
\text { Cutter Speed: } \\
\text { Number of Screens: } \\
\text { Cut Direction: } \\
\text { StrokeLength: }\end{array}$ & $\begin{array}{l}145 \mathrm{~mm} \\
\text { Not Installed } \\
\text { Not Installed } \\
141 \mathrm{~mm} \\
\text { Broach, 148mm } \\
70 \% \\
95 \% \\
10 \% \\
2 \mathrm{~s} \\
\text { On } \\
\text { On } \\
\text { Initial Angle } \\
0.2 \mathrm{~m} / \mathrm{s} \\
2600 \mathrm{rpm} \\
\text { Orpm (disabled) } \\
2 \\
\text { Upwards } \\
13 \mathrm{~m}\end{array}$ & $\begin{array}{l}\text { Top Ring Force: } \\
\text { Upper Ring Force: } \\
\text { Lower Ring Force: } \\
\text { Cutter Force } \\
\text { Depth of Cut } \\
\text { Starting Bore Width: } \\
\text { Ending Bore Width: } \\
\text { Cumulative Delta: } \\
\text { Cumulative Inclination: } \\
\text { Ice Area Cut: } \\
\text { Effective Stroke Length: } \\
\text { Ice Volume: } \\
\text { Screens Required: } \\
\text { Cumulative Chips Left: } \\
\\
\text { Model: } \\
\text { DrillNoRingsinitAngxmcC }\end{array}$ & $\begin{array}{l}213 \mathrm{~N} \\
\text { N/A } \\
\text { N/A } \\
259 \mathrm{~N} \\
3.5 \mathrm{~mm} \\
180.5 \mathrm{~mm} \\
184.0 \mathrm{~mm} \\
20.0 \mathrm{~mm} \\
3.34^{\circ} \\
518 \mathrm{~mm}^{2} \\
11.9 \mathrm{~m}^{2} \\
6.17 \mathrm{~L} \\
2.282 \text { Screens } \\
1.93 \text { Screens } \\
\end{array}$ \\
\hline
\end{tabular}

Fig. 6. With inputs defining the sonde configuration, the Mathcad model output above provides the critical parameters of each step of the deviation process. The lower window provides a graphical representation of the borehole, the sonde and its flexure. 


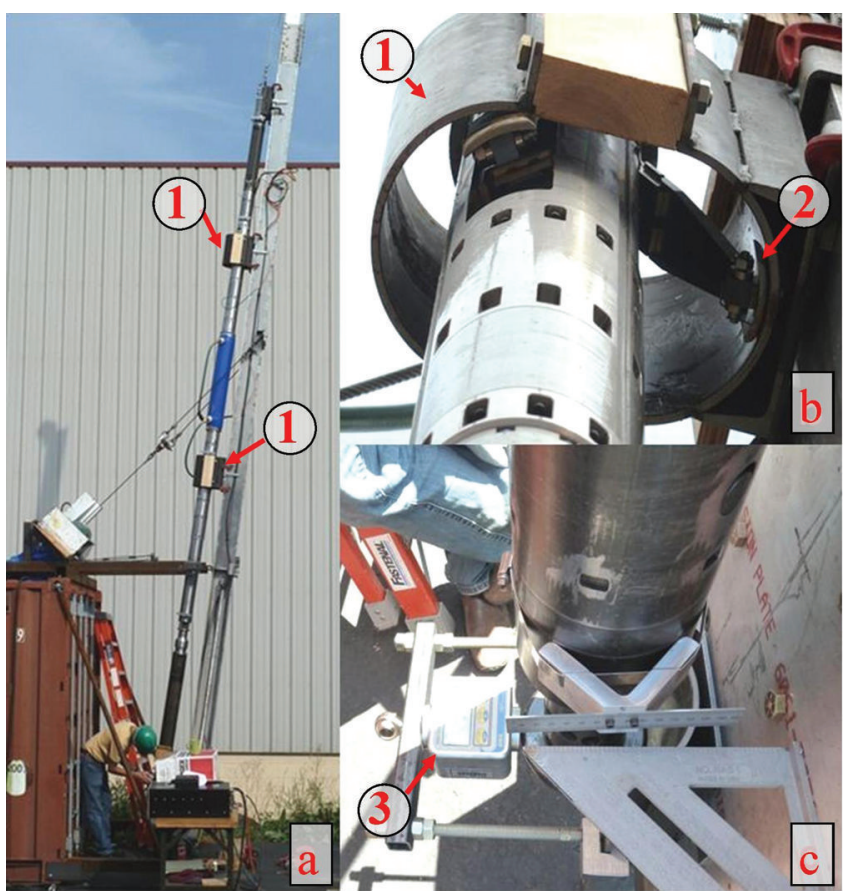

Fig. 7. (a) Test tower assembly. (b) Actuator with prototype levers (item 2) in steel tube (item 1) simulating oblong borehole cross section. (c) Load cell (item 3) measuring radial force at a cutter.

of the sonde exposed made it possible to measure the flexure of the drill by attaching rulers to the drill and tower and then measuring their displacement with a theodolite. Subtracting the movement of the tower from the total displacement of the sonde gave an accuracy of sonde flexure to better than $1 \mathrm{~mm}$ (Fig. 8). A fixture at the lower end of the tower measured the force at the cutter head using a load cell. Deflection and force measurements of specific configurations were incorporated into the model which was then used to model other drill configurations, eliminating the need for numerous manual measurements. With this approach, a drill plan was developed, predicting the progress of the deviation and providing the configuration of the drill at each step, including cutter and stabilizer ring diameters, and stabilizer ring locations.

The test set-up allowed visual inspection of the performance of the system in actual operating configuration for the first time. Another finding as a result of operating the drill on the test tower was that contact friction of the actuator levers was reduced with a new geometry, greatly increasing force at the cutter (Gibson and others, 2014). A prototype version of the levers is shown in Figure $7 \mathrm{~b}$. It also became evident that when pushing the sonde to an inclined position in an oval borehole it was advantageous to have the two actuator sections clocked in an alignment $180^{\circ}$ from each other. In this configuration, when lever No. 1 of the lower actuator section was positioned on the low side of the borehole, lever No. 1 of the upper actuator was directly opposite on the high side of the borehole, and maximum force at the cutter was achieved.

Additionally, with the entire drill visible on the tower, measurements could be made of the time required for the actuators to react to a given command and of the accuracy with which the system could find a desired azimuth. This information was useful during the final drilling season (2012/13).

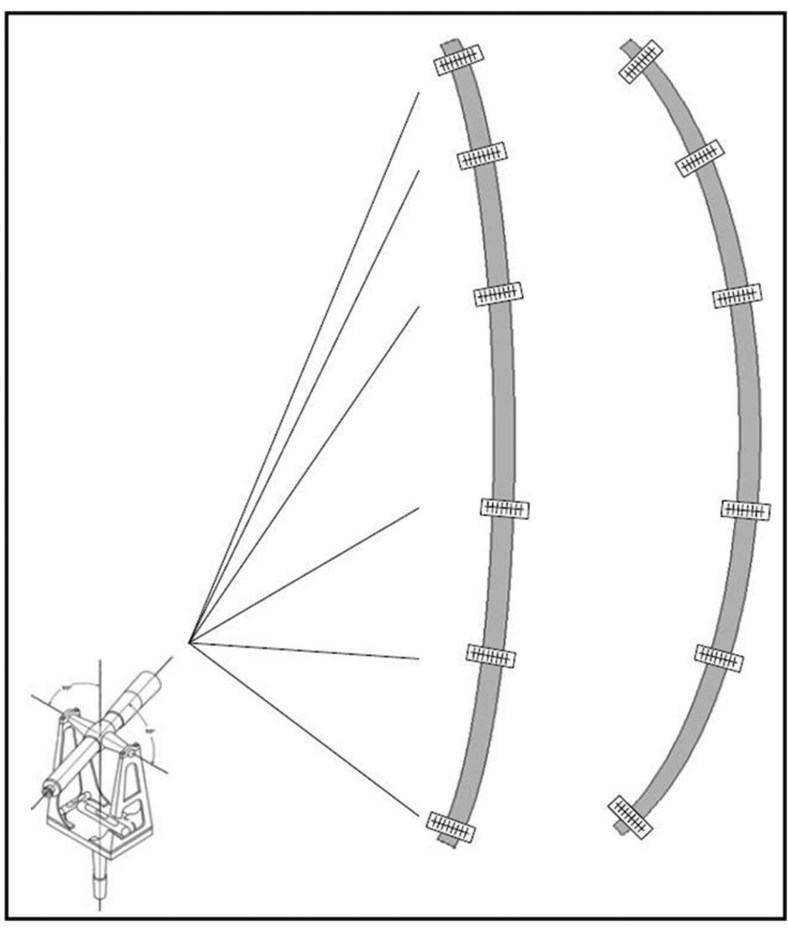

Fig. 8. Schematic of sonde flexure measurement using a theodolite and rulers rigidly fastened to the sonde at intervals along its length.

\section{CUTTER TESTING}

The 2011/12 field test revealed that the design and geometry of both the broaching and milling cutters needed to be refined. The ability of the broaching head to engage and stay engaged in the cut with the radial force that could be applied to it by the actuators needed to be verified. Field testing showed that the milling head needed to be better optimized for axial cutting, as opposed to radial cutting, since most of the cutting takes place in the axial direction. Also, cutter contact with the borehole wall needed to be minimized to reduce the tendency for the cutter to grab and precess (or orbit) around the hole. Additionally, the head design needed to be such that it could make a clean cut at high feed rates, estimated to be $50 \mathrm{~mm} \mathrm{~s}^{-1}$ during the slip phase of stick-slip motion.

A cutter test rig was built to address these challenges (Figs 9 and 10). A freezer large enough to contain the entire test ring was not available, so a chest freezer with a hole in the lid was used to keep the cutters and the ice cold. The rest of the test rig was mounted outside the freezer at room temperature. While the man-made ice does not have the exact properties of naturally occurring ice, it cut similarly and gave good comparative measurements between different cutter designs. A tank of drilling fluid was also chilled in the freezer and was used to fill the hole in the ice blocks while conducting cutter tests. Mounted above the freezer, a motorized slide was used to simulate axial drill motion. Rotary motion was provided by a motor attached to the slide through a load cell and gimbaled mount, which allowed free radial motion simulating a flexible drill string. Radial force, normally provided by the actuators, was simulated by a weight hanging on a rope that ran over a pulley and connected to a cutter motor. The load cell was used to record the axial force required to make a cut with the broaching or milling heads. This simple test set-up proved invaluable at optimizing the cutter geometries and verifying 


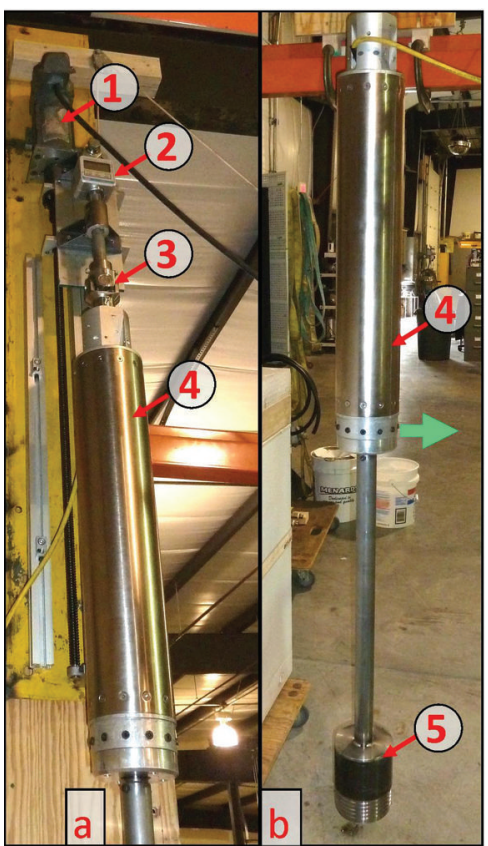

Fig. 9. Cutter-testing fixture. (a) An electric motor (1) is mounted above a linear slide providing axial translation of the entire cutter assembly. The cutter assembly includes a load cell (2) and a second motor for cutter rotation (4) mounted with a gimbaled joint (3). (b) The cutter rotation motor is attached to the cutter head with drive shaft and threaded cutter head adapter (5). The green arrow indicates the location on the non-rotating portion of the assembly where radial force is applied by means of a rope, pulley and weights.

that the new design met the operational requirements of the replicate coring system.

\section{BROACHING HEAD}

Based on the results of the tower testing, a design goal of a $100 \mathrm{~N}$ engagement force was established for the broaching cutter. Testing the existing broaching cutter with $15^{\circ}$ rake and relief angles (Fig. 2a) revealed that it required an engagement force of $>500 \mathrm{~N}$. The rake and relief angles were changed in $5^{\circ}$ increments until the geometry was found that required the lowest engagement force. The optimum cutter geometry was determined to have a $25^{\circ}$ rake angle and $20^{\circ}$ relief angle.

Even with this optimized geometry, the $100 \mathrm{~N}$ available was not enough force to ensure consistent cutter engagement and cutting. It was found that by adding a small serrated edge to the cutter and rotating it while broaching, the engagement force was reduced by as much as half. A serrated edge was implemented on the outside edge of the final cutter design using a knurling process.

The original head design allowed for multiple broaching cutters of different diameters to be stacked on the mandrel to give a progressive cut (Fig. 2a). This was scaled back to a single cutter mounted on a shorter head to maximize stiffness and to best utilize the radial force available. The final broaching head design is shown in Figure $2 \mathrm{~b}$. With the broaching cutter set to cut in the up stroke, the cutter should smoothly descend in the borehole.

A spring-energized bumper assembly had been designed to hold the cutter off the wall while ascending to the surface after broaching was completed (Fig. 11a). The bumper

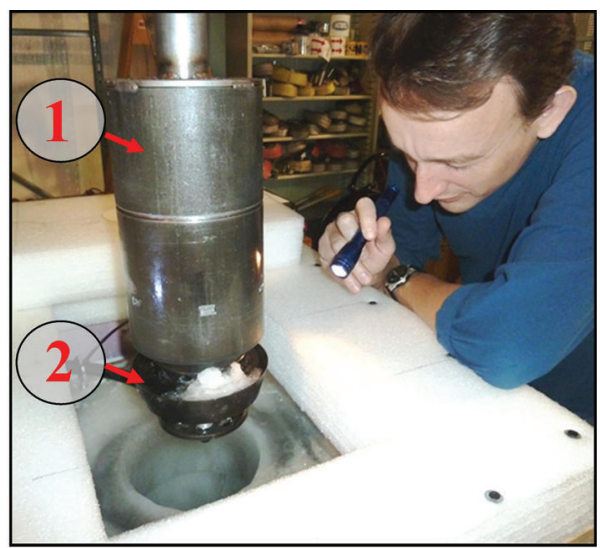

Fig. 10. Broaching cutter (2) is mounted to the cutter head adapter (1) of the cutter test fixture described in Figure 9. The ice block with borehole is visible beneath the polyethylene foam cover of the chest freezer in the lower part of the image.

performed well on the test tower; however, in operation at WAIS Divide during the 2012/13 season, the spring-loaded plungers did not apply enough force to keep the cutter from engaging in the borehole wall while tripping out of the hole. Adding heavier springs was not an option since this would reduce the force available for engaging and holding the broaching head in the cut.

A new method for preventing the cutter from engaging while tripping, called the drop ring, was devised and implemented during the field season. The basic concept of the system is to place a ring or sleeve around the body of the drill such that, when dropped to the cutter head, it keeps the cutter off the borehole wall. During broaching operations the ring would be stored further up the drill, over the motor section, where it would not interfere with cutting operations (Fig. 12).

Implementing this concept is a bit more involved than the bumper system. The drop-ring assembly, consisting of the drop ring, trigger assembly and ratchet ring, was implemented in phases to minimize downtime while the parts were being fabricated in the on-site machine shop. Initially, while the ratcheting ring and trigger assembly were being fabricated, the drop ring was held up in place by two strings tied between the rotating portion of the motor section (containing the drop ring) and the non-rotating portion. When the cutter motor was rotated, the strings would wind up and break, thus dropping the ring. The drop ring and strings are shown in Figure $11 \mathrm{~b}$.

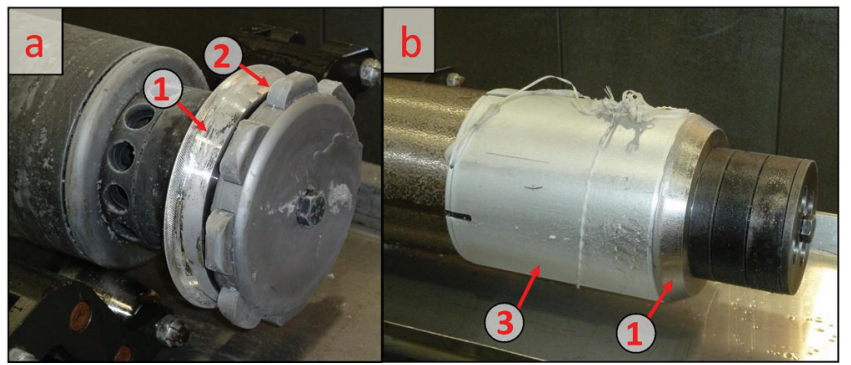

Fig. 11. (a) Broaching head with broaching cutter (1) and springenergized bumper assembly (2). (b) Drop ring with original string set-up (3) shrouding the broaching cutter (1). 

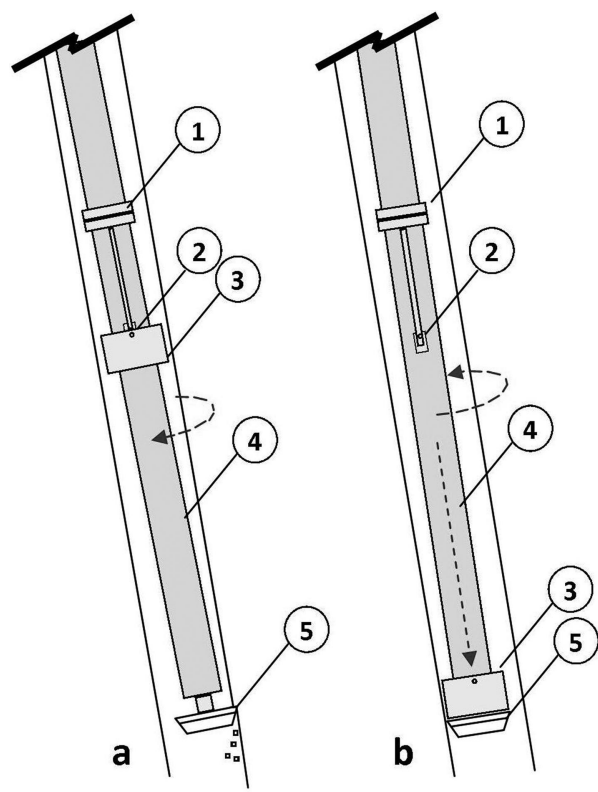

Fig. 12. (a) The sonde is deployed with the drop ring (3) latched at the top of the screen and core barrels (4). The ratchet ring (1) allows forward rotation of the barrels for deviation cutting without releasing the drop ring. (b) Reverse rotation depresses the trigger (2) holding the drop ring. The drop ring falls the length of the screen and core barrels and prevents any further engagement of the cutter (5) until the mechanism is reset at the surface.

In the completed version, the ring was held in place on the rotating portion of the motor section by a pin-and-trigger assembly. When the drill needed to be brought to the surface, the cutter motor was run in reverse for a few revolutions to energize the trigger assembly, which released the ring and dropped it down to the broaching cutter. The linear motion needed to operate the trigger assembly is generated by a cam profile on the downward face of a ratcheting ring, which is mounted on the non-rotating portion of the motor section. The ratchet feature permits the cutter motor to be rotated while broaching (permitting cutter engagement at a lower radial force) without dropping the ring. The ratchet ring locks when the motor is run in reverse, causing a follower to traverse the cam profile and generate the linear motion required to operate the trigger assembly. The complete drop-ring assembly is shown in Figure 13.

Collection of chips from the broaching operation was found to be much less efficient than expected despite the drill's high-flow pump (Mason and others 2007). This resulted in most of the cuttings being left in the borehole. This proved to be a benefit as it meant many broaching passes could be completed before the chip chamber filled and the drill needed to be brought to the surface. A large amount of the cuttings were found to float in the fluid column between 800 and $1250 \mathrm{~m}$. It was determined that dedicated cleaning runs were not necessary since they could be collected while the drill was descending for coring operations (Slawny and others, 2014).

\section{MILLING HEAD}

The geometry of the 12-tooth, $25 \mathrm{~mm}$ wide, saw blade-like cutters on the original milling head (Fig. 3a) was best suited for radial cutting. With a $0^{\circ}$ rake angle and only $5^{\circ}$ of relief

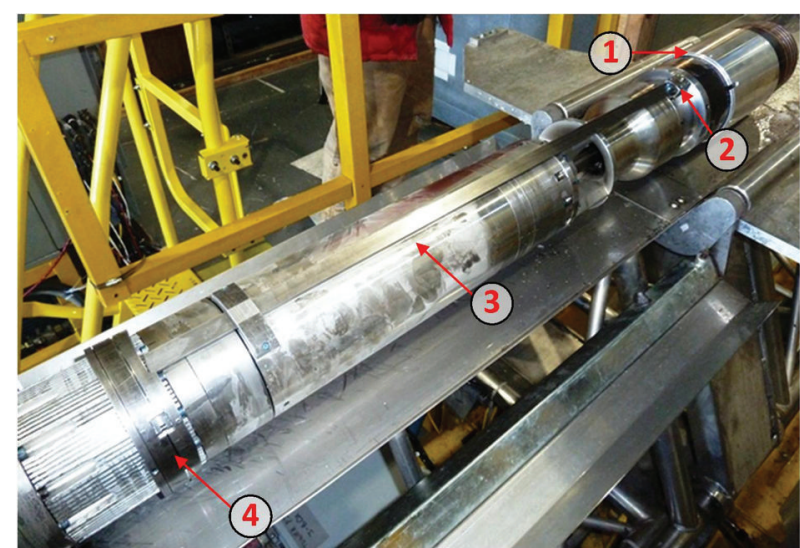

Fig. 13. Drop-ring assembly mounted on the motor section. The ratchet ring (4) surrounds the finned housing at the lower left. The trigger (2) and follower bar (3) are assembled between the ratchet ring and drop ring (1).

on the downward face-side of the cutter teeth, the geometry was inadequate for axial cutting, especially when in a stick-slip cutting mode. The wide teeth, with large contact area against the borehole wall, also made the head susceptible to precession around the borehole. With only two teeth, and originally no shoe, the face-milling cutters made for an uncontrolled and very aggressive cut in the axial direction. It was determined that the addition of a face shoe, in conjunction with creating a ledge in the borehole wall (on which the shoe could be placed) would control the cutting pitch, eliminate stick-slip and put the drill in a stable cutting mode. A helical face shoe (Fig. 3a) was made in the field. However, attempts to create the ledge failed. Analysis of the results of the WAIS Divide test season showed that a milling head was needed that was optimized for axial cutting and that could accommodate short-duration feed rates estimated at $50 \mathrm{~mm} \mathrm{~s}^{-1}$. Additionally, implementing adjustable shoes to limit the cutting depth for both radial and axial cutting was important. A new milling head was built based on these design considerations and is shown in Figure $3 \mathrm{~b}$. Six cutters, with a $30^{\circ}$ rake angle and $9^{\circ}$ relief angle, were chosen as a good balance between an open head design and having enough teeth to provide a reasonable feed rate per tooth. Radial clearance from cutter tip to barrel provides a $4 \mathrm{~mm}$ radial depth of cut. The cutter height provides for a smooth cut with up to a $12 \mathrm{~mm}$ per tooth feed rate to accommodate the stick-slip cutting mode. To help load the cutter towards the borehole wall while face milling, the downward-facing edge of the cutters inclines $5^{\circ}$ up towards the center. This also helps prevent the cutter from walking and keeps it centered when engaged in a large face cut. Axial stick-slip proved to be a continued problem during the 2012/13 drilling season. Broaching cuts are made in the up stroke, resulting in a curve $\sim 1.0 \mathrm{~m}$ long at the bottom of the deviation where it tapers back to the parent hole. This transition needs to be removed, creating a flat ledge at least $75 \mathrm{~mm}$ deep, in order to begin coring operations. This is to ensure a core can be recovered by the core dogs on the first coring run. During stick-slip motion the linear feed rate of the drill exceeds the clearing capacity of the cutters. The milling head will not cut the diverging profile needed to steer the replicate coring drill out of the parent borehole. Rather, the milling head will leave a helical cut, making no 
sideways cutting progress, and be pushed back into the parent hole following the ramp profile left by the broaching process. By repeatedly cutting the upper portion of this ramp, with the milling head configured without face shoes, sideways progress was eventually made and a shallow ledge was formed. The face shoes were then reinstalled; the milling head was set on the ledge and, with the drill in a stable cutting mode, the last meter or so of the ramp was removed. To increase the efficacy of this initial step of creating the ledge, a downward-facing broaching tooth was fabricated in the field that mounts in place of the face shoes as shown in Figure 14. The diameter of this tooth was such that the milling cutters would hold it off the borehole wall with a clearance of $\sim 1 \mathrm{~mm}$ while the drill was descending to depth. However, when the head was rotating and the feed rate exceeded its permissible clearing rate, the tooth would engage, making some sideways progress with each pass, and also help to decelerate the drill. This worked very well and reduced the time required to create the initial ledge.

\section{ELECTRONICS AND CONTROL SYSTEM}

Several improvements to the electronics and control system were identified through the field testing of the replicate coring system at WAIS Divide.

During the deviation process, the sonde occasionally rotated around its central axis due to any of a number of interactions between the borehole and the sonde. The drill logic had no way of correcting for this rotation, so an 'AutoAzimuth' feature was added that continuously scans the orientation of the drill and sends a corrected deviation direction to the replicate system such that the drill could deviate straight instead of helically.

The initial test season also demonstrated that a hall-effect position feedback system in the actuator section, used to tell the operator the position of each lever, was susceptible to electrical noise and therefore did not provide reliable feedback. This system was replaced with a system using a linear variable differential transducer (LVDT) (Gibson and others, 2014; Mortensen and others, 2014). Further testing at IDDO of the LVDT system yielded some necessary enhancements to the LabVIEW control software. Each specific LVDT was found to behave slightly differently, so individual calibration values were added to the software to allow standardization.

Additionally, because the lever arms move with an arc motion, the force the levers exert on the borehole changes in relation to how far they are extended for a given power applied to the motors. Because of this, a skew table was created and implemented into the control system in order to correct for these variations.

Within the LabVIEW graphical user interface, the initial test season yielded additional areas for potential improvements. First, the data connection between the drill and the surface computers became bogged down by a slew of small individual data packets, one for each sensor. A bulk data command protocol was developed that allowed each drill sensor to send its data in one universal data packet and this successfully brought the data rate back to an acceptable level. Second, testing revealed the possibility that the surface software could assign the drill a different state of operation than that assigned in the onboard drill software. Because of this, software was updated to periodically sync

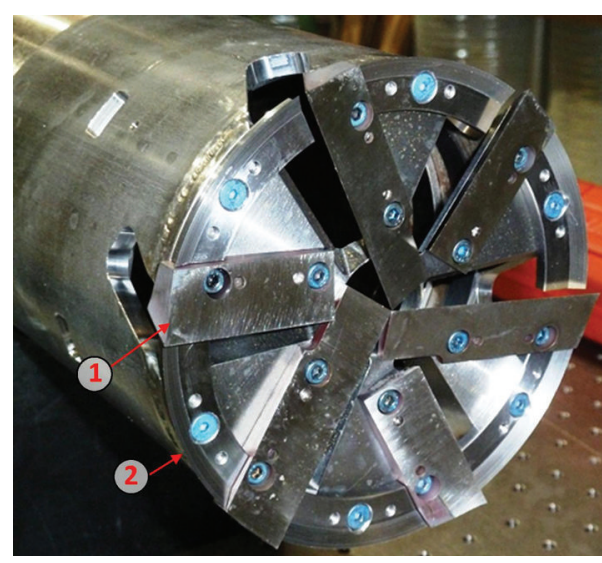

Fig. 14. Milling head with broaching tooth cutters. 1: Face cutter, qty $6 ; 2$. broaching tooth, qty 6 .

the two systems, allowing the drillers to have reliable knowledge of the drill's behavior. Finally, it was discovered through field testing that no standard behavior was described for the lever arms when the drill software changed between automatic and manual modes. Sometimes the levers would fully retract, sometimes fully extend and sometimes pause. LabVIEW was updated to always send a 'retract-all' command with this state change in order to ensure uniform operation.

\section{BOREHOLE CAMERA}

A borehole imaging system was included with the replicate coring system to provide visual verification of the deviation process. The original design integrated a Multi SeaCam 2065 submersible camera from DeepSea Power \& Light with a pressure vessel containing a transmitter for sending a realtime video signal to the surface over the fiber optics in the winch cable and a power supply to power the transmitter and camera. The borehole was illuminated by a ring of LEDs, which are an integral part of the camera and surround the camera lens. The original camera system was connected directly to the DISC drill's anti-torque section, requiring the rest of the drill to be taken offline each time the camera was to be deployed. This proved to be a time-consuming job. Overall, the system functioned well. Nevertheless, it was often difficult to see the borehole wall with any clarity because the cuttings suspended in the drilling fluid were being illuminated and reflecting light back to the camera. This can clearly be seen in Figure 15a. This lighting issue was addressed by adding a light source ahead of the camera. The custom-built light housing contains 36 LEDs, which are exposed to the drilling fluid and borehole pressure, and a diffuser to ensure the light is evenly dispersed in the borehole. The result is a clear backlit view of the borehole between the camera and light head because particles in the drilling fluid are not reflecting light back at the camera as shown in Figure 15b. To make the system easier to deploy, the camera system was reconfigured so it could be installed inside the core barrel so there was virtually no changeover time from drilling operations to camera deployment (Fig. 16). Since the camera would no longer be connected directly to the winch cable, the components in the pressure vessel were replaced with a self-contained recording device and battery pack to power the recording device and camera. 


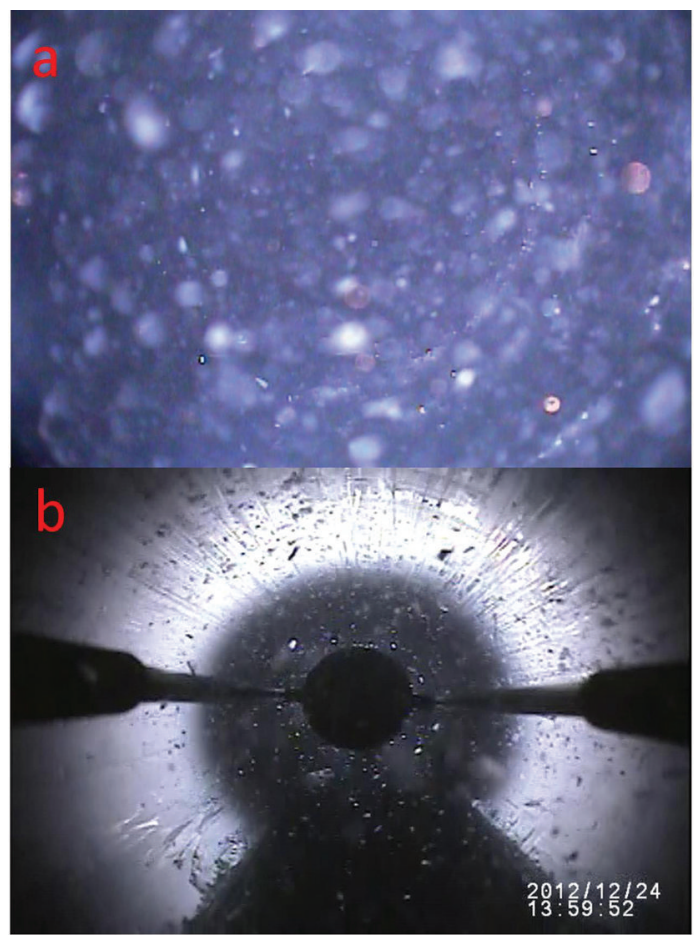

Fig. 15. (a) Image of borehole illuminated with LED light ring surrounding the camera lens. (b) Image of borehole illuminated with forward light head. The dark area in the lower part of this image is the replicate deviation.

\section{SUMMARY}

Initial field testing of the replicate coring system revealed the need for some refinements to the mechanical and electronic systems. Managing axial stick-slip, sonde flexure, and refining the design of the broaching and milling cutters were the three main areas that needed to be addressed. FEA and analytical models were constructed and subsequently refined and calibrated using deflection measurements taken from the actual drill. Two test rigs were built: one for testing the physical and operational aspects of the drill system, and a second for testing cutter designs in ice. The broaching and milling heads were redesigned and optimized based on the results of the test season and tower testing. A drilling plan was made based on the analytical model and was used to guide drilling operations during the final drilling season. Further refinements to the replicate coring process continued during production drilling including adding the drop ring to the broaching head, adding broaching teeth for the milling head and updating the drill plan. Visual inspection of the deviations was done using a borehole camera

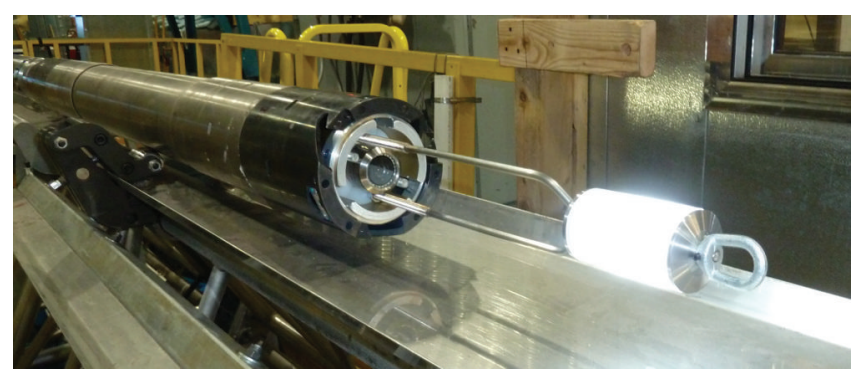

Fig. 16. Borehole camera with forward light head installed in the replicate core barrel.

modified to fit into the core barrel to reduce change over time and fitted with a newly designed forward light that permitted greatly improved image quality in drilling fluid containing suspended cuttings.

\section{ACKNOWLEDGEMENTS}

A tremendous amount of work and planning went into testing and refining the replicate coring system, which led to the success of the 2012/13 replicate coring season at WAIS Divide. Ice Drilling Design and Operations expresses our sincere gratitude to the numerous people and organizations that helped make this happen. We express special gratitude to SSEC staff, IDDO's Technical Advisory Board (TAB), the Ice Drilling Program Office (IDPO) and Bjorksten | bit 7 for their strong support. We thank the US National Science Foundation (NSF) Office of Polar Programs (OPP) for ongoing support and funding. This work was supported under NSF OPP Award No. 0841135.

\section{REFERENCES}

Gibson CJ, Johnson JA, Shturmakov AJ, Mortensen NB and Goetz JJ (2014) Replicate ice-coring system architecture: mechanical design. Ann. Glaciol., 55(68) (doi: 10.3189/2014AoG68A019) (see paper in this issue)

Mason WP, Shturmakov AJ, Johnson JA and Haman S (2007) A new $122 \mathrm{~mm}$ electromechanical drill for deep ice-sheet coring (DISC): 2. Mechanical design. Ann. Glaciol., 47, 35-40 (doi: 10.3189/172756407786857640)

Mortensen NB, Goetz JJ, Gibson CJ, Johnson JA and Shturmakov AJ (2014) Replicate ice-coring system architecture: electrical, electronic and software design. Ann. Glaciol., 55(68) (doi: 10.3189/2014AoG68A014) (see paper in this issue)

Slawny KR and 7 others (2014) Production drilling at WAIS Divide. Ann. Glaciol., 55(68) (doi: 10.3189/2014AoG68A018) (see paper in this issue) 